\title{
Влияние условий предварительного прогрева активных углей на адсорбцию органических соединений из водных растворов
}

\author{
Беляева О.В., Краснова Т.А., Голубева Н.С. \\ ФГБОУ ВПО «Кемеровский технологический институт пищевой промышленности (университет)», \\ Кемерово
}

Поступила в редакцию 21.07.2017 г.

Исследовано влияние условий предварительного прогрева в окислительной среде (воздух) активного угля (АУ) на адсорбцию из водных растворов анилина, пиридина и фенола. Полученные изотермы адсорбции описаны с применением теорий БЭТ и Дубинина - Радушкевича. Установлено, что прогрев на воздухе повышает адсорбцию пиридина и анилина, тогда как изменение адсорбции фенола находится в пределах погрешности эксперимента.

Ключевые слова: активные угли, адсорбция, пиридин, анилин, фенол.

\section{The effect of pre-heating conditions of active carbons on the adsorption of organic compounds from aqueous solutions}

\author{
Belyaeva O.V., Krasnova T.A., Golubeva N.S. \\ Kemerovo Institute of Foot Science and Technology, Kemerovo
}

\begin{abstract}
The effect of preliminary heating of active carbon in an oxidizing atmosphere under the conditions when the accumulation of surface compounds of oxygen prevails over the process of destruction of the organic part of the carbon adsorbent in adsorption of organic compounds was investigated. It was determined that during the heat treatment in the chosen conditions a redistribution of the volume of micro and mesopores of the adsorbent occurs, as well as the change in the amount of titratable surface acid and basic groups on the surface of active carbon. The equilibrium adsorption of phenol, aniline and pyridine from aqueous solutions with heated samples of active carbon was studied. It was established that the form of adsorption isotherms of studied species suggests a strong specific interaction of sorbent - sorbate. It was revealed that the adsorption of organic components is influenced not only by the characteristics of the porous structure and the chemical state of the surface of adsorbent, but also the molecule structure of the adsorbtion. Heat treatment of the adsorbent at the chosen conditions has little effect on the adsorption of phenol, but significantly increases the adsorption of pyridine. In the case of aniline a discernible increase in adsorption is observed only for the sample of active carbon, heated at $250^{\circ} \mathrm{C}$. The resulting adsorption isotherms were analyzed in the linearized coordinates of the equations of BET and TMVF (Dubinin - Radushkevich). It was determined that the monomolecular adsorption of all studied organic substances is realized by specific interaction of adsorbent adsorbate, the type of which (hydrogen bond and/or donor-acceptor interaction) depends on the prevalence of acidic or basic groups on the surface of the adsorbent. The formation of the second layer of the component occurs due to the dispersion interactions. The calculated value of the maximum adsorption volume occupied by aniline and phenol, assumes volume filling of micro - and mesopores of activated carbon. Upon the adsorption of pyridine a mixed adsorption layer is formed on all the samples of activated carbon. The ratio of organic material - solvent in this layer depends on the surface characteristics of the adsorbents. The proportion of pyridine, even for the sample heated at $250^{\circ} \mathrm{C}$, does not exceed $35 \%$ in the formation of the first layer on the carbon surface and $70 \%$ in the volumetric filling of micropores. In the case of phenol, for which dis-
\end{abstract}


persive interactions with the carbon surface are more typical, increased adsorption due to the rise in the number of carbonyl/quinoid groups is compensated by the decrease in the total pore volume of the adsorbent and increased adsorption of the solvent (water).

Keywords: activated carbon, adsorption, pyridine, aniline, phenol.

\section{Введение}

Общеизвестно, что при выборе адсорбентов обращают внимание на совокупность характеристик структуры и состояния их поверхности. Активные угли неоднородны как по структуре, так и по химическому составу. На их поверхности наиболее часто реализуется неспецифическая адсорбция за счет суммарного действия дисперсионного, индукционного и ориентационного взаимодействий молекул адсорбатов с базисными гранями графита $[1,2]$. Кроме того, в процессе карбонизации и активации на поверхности активных углей образуются функциональные соединения кислорода кислотного (фенольные, карбоксильные группы) и основного (хиноидные, пиронные и хроменовые группы) характера [3-4]. Для ароматических соединений наличие в структуре бензольного кольца или функциональных групп с гетероатомом предполагает также возможность электростатического (специфического) взаимодействия сорбент - сорбат с образованием как водородной связи с протонодонорными поверхностными активными группами (кислотами Бренстеда), так и комплексов с переносом заряда с апротонными центрами Льюиса на поверхности активного угля [3-10]. Эти же поверхностные функциональные группы могут выступать в качестве первичных центров адсорбции молекул воды $[2,11]$.

Пористые адсорбенты рекомендуется предварительно прогревать для удаления поглощенных при хранении газообразных веществ и паров воды. Температура прогрева углеродных материалов варьируется от 105 до $300^{\circ} \mathrm{C}[12,13]$. При этом согласно Тарковской [14], поверхность углерода способна хемосорбировать кислород с образованием дополнительных поверхностных соединений кислорода, качественный состав которых зависит от условий прогрева. Кроме того, прогрев на воздухе может приводить к деструкции кислородом углеродной поверхности, интенсивность которой также зависит от температуры. Оба процесса (образование поверхностных соединений кислорода и разрушение органической массы угля) будут протекать параллельно, преобладание какого-либо из них будет зависеть от условий термической обработки. Причем, если первый процесс способен повысить адсорбцию полярных соединений за счет специфической адсорбции, то второй - уменьшить из-за снижения количества потенциальных центров адсорбции за счет дисперсионного взаимодействия.

Предварительные термогравиметрические исследования показали [15], что для АУ марки АГ-ОВ-1 при температуре $110^{\circ} \mathrm{C}$ заканчивается удаление адсорбированной на поверхности воды, а при температуре выше $310^{\circ} \mathrm{C}$ начинается процесс горения адсорбента. Поэтому предварительный прогрев предполагается проводить внутри данного температурного интервала.

Целью данной работы являлось изучение влияния условий предварительной термической обработки адсорбента на адсорбцию из разбавленных водных растворов анилина, пиридина и фенола.

\section{Эксперимент}

Объектом исследования был выбран активный уголь марки АГ-ОВ-1 (НПО «Сорбент», Пермь), который предварительно отмывался дистиллированной водой от пылевых фракций и высушивался до воздушно-сухого состояния (образец I). Затем

Беляева и др. / Сорбционные и хроматографические процессы. 2017. Т. 17. № 6 
одна часть подготовленного таким образом АУ подвергалась прогреву в термостатируемом шкафу с принудительной вентиляцией при $120 \pm 1.0^{\circ} \mathrm{C}$ в течение 8 ч (образец II), а другая - при $250 \pm 1.0^{\circ} \mathrm{C}$ в течение 5 ч (образец III).

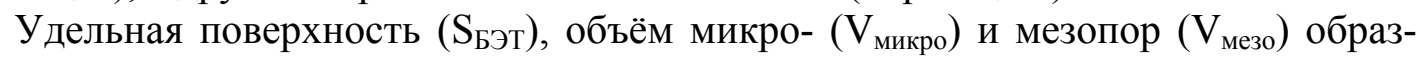
цов АУ определялись по низкотемпературной адсорбции азота. Общее количество титруемых кислотных и основных групп на поверхности адсорбентов оценивалось по реакции обмена с растворами $\mathrm{NaOH}\left(\mathrm{COE} \mathrm{OH}^{-}\right)$и $\mathrm{HCl}\left(\mathrm{COE} \mathrm{H}^{+}\right)$соответственно.

Адсорбция органических веществ изучалась в статических условиях на модельных растворах при соотношении навеска адсорбента:объем исследуемого раствора, равном 1:100, с концентрацией компонентов 0.05-2.0 г/дм³ ${ }^{3}$ Определение равновесной концентрации веществ проводилось по собственному поглощению растворов в УФ-области на приборе $C Ф-46$ (ЛОМО) методом абсолютной калибровки: пиридина при 256 нм ( $\varepsilon=7650$ дм $^{3} /($ моль см $\left.), \mathrm{S}_{\mathrm{r}}=0.007\right)$; анилина при 230 нм ( $\varepsilon=6986$

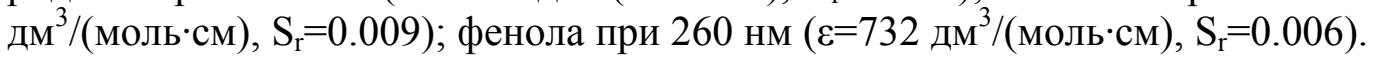

Для количественного описания равновесия адсорбции использовались модели БЭТ и Дубинина - Радушкевича, модифицированные для случая адсорбции из водных растворов хорошо растворимых и смешивающихся при любых соотношениях веществ [16-18].

Модель БЭТ использовалась для описания полимолекулярной адсорбции:

$$
\Gamma=\Gamma_{\infty} \frac{K_{L} C_{p}}{\left(1-K_{S} C_{p}\right)\left(1-K_{S} C_{p}+K_{L} C_{p}\right)},
$$

где $\Gamma$ - избыточная адсорбция Гиббса, моль $/ \Gamma ; \Gamma_{\infty}$ - емкость насыщенного монослоя, моль/г; $K_{L}$ и $K_{S}$ - константы сорбционного равновесия при образовании мономолекулярного и полимолекулярного слоя соответственно, Дж/моль; $C_{p}-$ равновесная концентрация раствора, моль/дм³ ${ }^{3}[17]$.

Величина теплоты адсорбции определялась по формуле [19]:

$$
-Q=R T \ln (K+1),
$$

где $K$ - соответствующая константа сорбционного равновесия, Дж/моль.

Удельная поверхность адсорбента, заполненная компонентом, оценивалась по формуле [19]:

$$
S=\Gamma_{\infty} \cdot S_{0} \cdot N_{a}
$$

где $S_{0}$ - площадь, занимаемая одной молекулой адсорбата в адсорбционном слое, м $^{2}$; $N_{a}$ - постоянная Авогадро, моль ${ }^{-1}$.

Для описания адсорбции в порах адсорбента использовали теорию объемного заполнения микропор ТОЗМ (модель Дубинина - Радушкевича) [18]:

$$
\Gamma=\frac{W_{0}}{V_{M}} \exp \left(-\left(\frac{R T}{E \beta} \ln \left(\frac{1}{C_{p} \gamma}\right)\right)^{2}\right),
$$

где $\Gamma$ - избыточная адсорбция Гиббса, моль/г; $W_{0}$ - предельный объём адсорбционного пространства, $\mathrm{cm}^{3} / \Gamma ; E$ - характеристическая энергия адсорбции, кДж/моль; $V_{M}$ мольный объем адсорбата, см $^{3} /$ моль; $C_{p}$ - равновесная концентрация раствора, моль/дм ${ }^{-3} ; \gamma$ - коэффициент активности; $\beta$ - коэффициент аффинности.

\section{Обсуждение результатов}

Исследования пористой структуры и состояния поверхности АУ показали (табл. 1), что при прогреве в выбранных условиях происходит перераспределение объема микро- и мезопор за счет "травления" поверхности последних. Изменение 
количества титруемых поверхностных соединений зависит от температуры прогрева: при $120^{\circ} \mathrm{C}$ наблюдается снижение как кислотных, так и основных групп, вероятно за счет их перехода в «неактивные» простые эфирные и хиноидные (карбонильные) структуры; при $250^{\circ} \mathrm{C}$ возрастает количество как кислотных, так и основных групп, причем последних - в большей степени.

Таблица 1. Характеристика пористой структуры и состояния поверхности образцов AY

\begin{tabular}{|c|c|c|c|c|}
\hline \multicolumn{2}{|c|}{ Образец АУ } & $\mathrm{I}$ & II & III \\
\hline \multicolumn{2}{|c|}{$\mathrm{S}_{\text {БЭТ }}, \mathrm{M}^{2} / \Gamma$} & $686 \pm 29$ & $654 \pm 31$ & $619 \pm 39$ \\
\hline \multicolumn{2}{|c|}{$\mathrm{V}_{\text {мезо }}, \mathrm{cm}^{3} / \Gamma$} & $0.24 \pm 0.02$ & $0.15 \pm 0.01$ & $0.15 \pm 0.01$ \\
\hline \multicolumn{2}{|c|}{$\mathrm{V}_{\text {микро }}, \mathrm{cm}^{3} / \Gamma$} & $0.22 \pm 0.02$ & $0.30 \pm 0.02$ & $0.27 \pm 0.02$ \\
\hline \multirow{2}{*}{ СОЕ, ммоль/г } & $\mathrm{OH}^{-}$ & $0.32 \pm 0.01$ & $0.20 \pm 0.01$ & $0.46 \pm 0.02$ \\
\hline & $\mathrm{H}^{+}$ & $0.48 \pm 0.02$ & $0.42 \pm 0.02$ & $0.72 \pm 0.04$ \\
\hline
\end{tabular}

Изотермы адсорбции исследуемых веществ (рис.1) можно отнести к Н-2 типу по классификации Гильса, что предполагает сильное специфическое (или химическое) взаимодействие сорбент - сорбат [20]. Установлено, что на адсорбцию органических соединений влияют не только характеристики адсорбента, но и структура адсорбтивов. Адсорбция фенола одинакова (в пределах погрешности эксперимента) для всех образцов адсорбента. Прогрев при $120^{\circ} \mathrm{C}$ мало меняет адсорбцию анилина, тогда как термообработка при $250^{\circ} \mathrm{C}$ приводит к ее росту. Адсорбция пиридина резко повышается (по сравнению с исходным активным углем) для всех прогретых образцов.
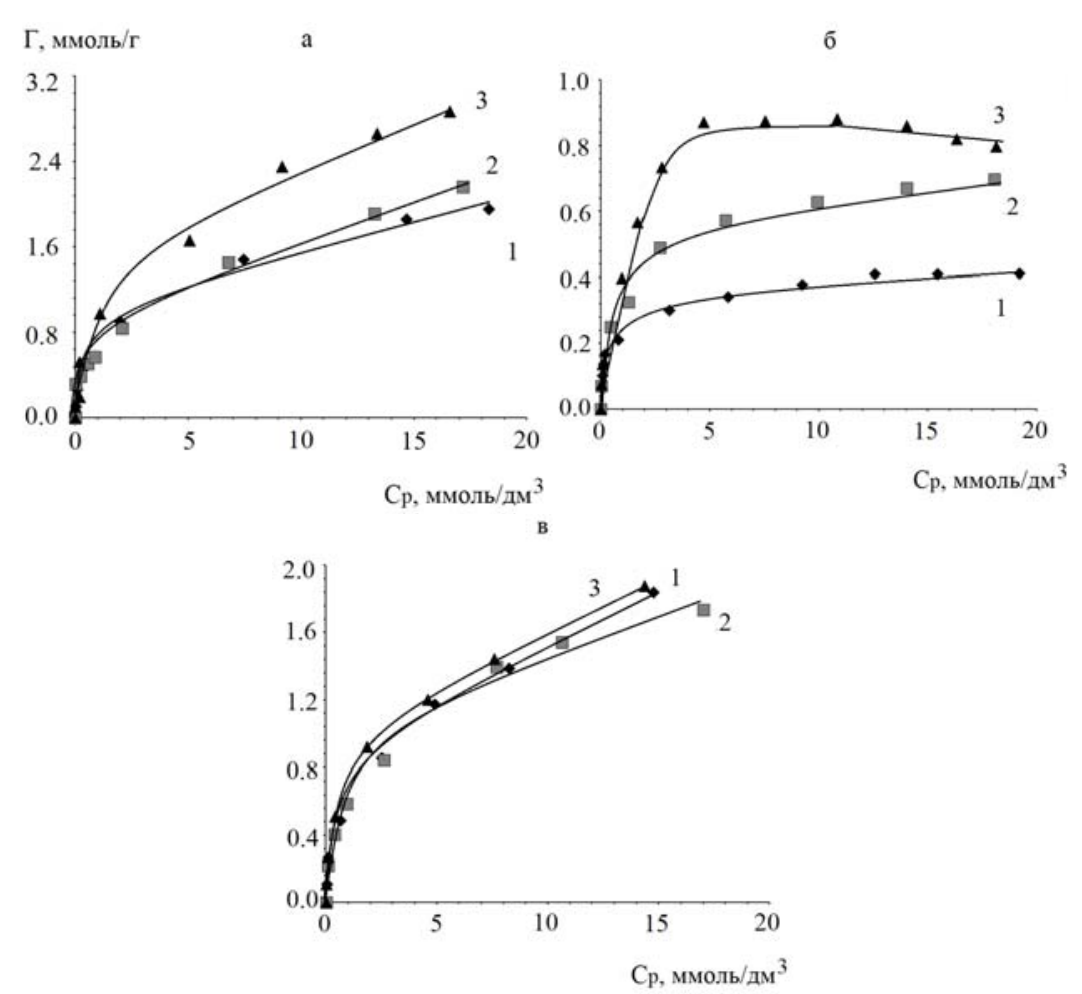

Рис. 1. Изотермы адсорбции анилина (а), пиридина (б) и фенола (в) образцами активного угля: 1- исходного (I); 2- прогретого при $120^{\circ} \mathrm{C}$ (II); 3- прогретого при $250^{\circ} \mathrm{C}$ (III). 
Для количественного определения параметров равновесия адсорбции использовали линеаризированные уравнения моделей БЭТ и ТОЗМ. Полученные значения и коэффициенты корреляции $\left(\mathrm{R}^{2}\right)$ представлены в табл. 2.

Таблица 2. Параметры адсорбции органических веществ образцами активных углей, рассчитанные с использованием моделей ТОЗМ и БЭТ

\begin{tabular}{|c|c|c|c|c|c|c|c|c|}
\hline \multirow{3}{*}{ AУ } & \multicolumn{3}{|c|}{ модель ТОЗМ } & \multicolumn{5}{|c|}{ модель БЭТ } \\
\hline & \multirow{2}{*}{$W_{0}, \mathrm{~cm}^{3} / \Gamma$} & \multirow{2}{*}{$\begin{array}{c}E, \\
\text { кДж/моль }\end{array}$} & \multirow{2}{*}{$\mathrm{R}^{2}$} & & $-Q_{L}$ & $-Q_{S}$ & \multirow{2}{*}{$S, \mathrm{м}^{2} / \Gamma$} & \multirow{2}{*}{$\mathrm{R}^{2}$} \\
\hline & & & & ммоль/дм ${ }^{3}$ & \multicolumn{2}{|c|}{ кДж/моль } & & \\
\hline \multicolumn{9}{|c|}{ нилин } \\
\hline I & $0.23 \pm 0.01$ & 11.98 & 0.99 & $1.55 \pm 0.08$ & 17.39 & 6.23 & $388 \pm 19$ & 0.99 \\
\hline II & $0.28 \pm 0.02$ & 10.02 & 0.98 & $1.53 \pm 0.08$ & 17.06 & 7.02 & $383 \pm 19$ & 0.99 \\
\hline III & $0.33 \pm 0.02$ & 11.69 & 0.99 & $1.89 \pm 0.09$ & 17.12 & 7.63 & $475 \pm 24$ & 0.99 \\
\hline \multicolumn{9}{|c|}{ фенол } \\
\hline I & $0.25 \pm 0.02$ & 14.12 & 0.99 & $1.44 \pm 0.10$ & 16.92 & 6.39 & $382 \pm 27$ & 0.99 \\
\hline II & $0.23 \pm 0.02$ & 14.23 & 0.98 & $1.34 \pm 0.09$ & 16.96 & 6.87 & $354 \pm 25$ & 0.99 \\
\hline III & $0.26 \pm 0.02$ & 14.26 & 0.99 & $1.39 \pm 0.10$ & 18.04 & 6.97 & $369 \pm 26$ & 0.99 \\
\hline \multicolumn{9}{|c|}{ пиридин } \\
\hline I & $0.07 \pm 0.00$ & 21.43 & 0.97 & $0.37 \pm 0.02$ & 19.65 & 4.48 & $86 \pm 4$ & 1.00 \\
\hline II & $0.13 \pm 0.01$ & 18.91 & 0.99 & $0.62 \pm 0.03$ & 17.86 & 4.68 & $144 \pm 7$ & 0.99 \\
\hline III & $0.19 \pm 0.01$ & 18.66 & 0.96 & $0.86 \pm 0.04$ & 18.20 & 5.04 & $201 \pm 10$ & 1.00 \\
\hline
\end{tabular}

Значения предельной емкости монослоя $\left(\Gamma_{\infty}\right)$ и удельной поверхности адсорбента $(S)$, занимаемой пиридином свидетельствует об отсутствии монослоя чистого компонента. Вероятнее всего, при адсорбции образуется смешанный слой пиридин вода, что характерно для хорошо и неограниченно растворимых веществ [1]. Соотношение адсорбатов в приповерхностном слое зависит от условий прогрева образцов активного угля.

Величины теплоты адсорбции $\left(Q_{L}\right)$ для всех адсорбатов (табл. 2) сопоставимы с энергией электростатического взаимодействия (энергия диполь - дипольного взаимодействия составляет 5-20 кДж/моль, водородной связи - 12-60 кДж/моль [21]), что подтверждает наличие специфического взаимодействия исследуемых компонентов с поверхностью активных углей при образовании монослоя. При формировании второго слоя компонента взаимодействие происходит за счет Ван-дер-Ваальсовых сил $\left(Q_{S}<8\right.$ кДж/моль), возможно также слабое диполь - дипольное взаимодействие.

Рассчитанный предельный адсорбционный объем, занимаемый компонентом $\left(W_{0}\right)$, показывает, что пиридин, в отличие от анилина и фенола, в порах также адсорбируется в смеси с водой. Величина характеристической энергии адсорбции $(E)$ предполагает, что все исследуемые вещества при адсорбции занимают доступные по размеру микро- и мезопоры.

\section{Заключение}

Предварительный прогрев адсорбента, особенно при $250^{\circ} \mathrm{C}$, повышает адсорбцию азотсодержащих соединений (в большей степени пиридина) и не изменяет адсорбцию фенола. Подобное различие в адсорбционном поведении исследуемых веществ, связано, вероятно, с особенностями их взаимодействия с углеродной поверхностью.

Для фенола и анилина характерна, в основном, адсорбция за счет неспецифического (в основном дисперсионного и ориентационного) взаимодействия [1]. Специфическая адсорбция фенола также может реализоваться при диполь-дипольном 
взаимодействии заместителя $(-\mathrm{OH})$ не только с протонодонорными группами, но и с основными (например, хиноидными) центрами на углеродной поверхности [9]. Возможно также образование комплексов с переносом заряда между бензольным кольцом и карбонильными/хиноидными поверхностными соединениями [10]. Вероятно, рост адсорбции фенола за счет увеличения доли карбонильных/хиноидных групп компенсируется снижением за счет уменьшения суммарного объема пор адсорбента. При этом также следует учесть, что увеличение поверхностных соединений кислорода может привести к повышению адсорбции растворителя (воды) и усилению конкуренции за первичные адсорбционные центры.

Для анилина помимо комплексов с переносом заряда, возможно образование водородной связи между неподеленной парой азота аминогруппы и карбоксильной/фенольной группами активного угля, изменение содержания которых в процессе прогрева, возможно, и приводит к росту адсорбции этого компонента образцом III.

Для пиридина при адсорбции из водных растворов характерно преимущественно специфическое взаимодействие как неподеленной пары азота ароматического кольца с поверхностными соединениями кислорода кислотного типа, так и комплексов с переносом заряда. Доля молекул, адсорбированных за счет дисперсионного взаимодействия, низка. Увеличение специфических адсорбционных центров на поверхности адсорбента приводит к перераспределению соотношения пиридин - растворитель (вода) на поверхности активного угля в сторону увеличения доли органического вещества.

\section{Список литературы}

1. Когановский А.М. , Клименко Н.А. и др. Адсорбция органических веществ из воды. Л. Химия. 1990. $256 \mathrm{c.}$

2. Котельникова Т.А., Кузнецов Б.В. и др. // Сорбиионные и хроматографические проuесcы. 2012. Т. 12. № 4. C.523-540.

3. Yang R.T. Adsorbents: fundamentals and applications. London-New York. Wiley Interscience Publ. 2003. 410 p.

4. Солдатов А.И. // Вестн. Челяб. ун-та. Сер. 4. Химия. 2004. № 1. С. 76-80.

5. Nevskaia D.M., Castillejos-Lopez E. et al // Carbon. 2004. Vol. 42. pp. 653-665.

6. Radovic L. R., Silva I.F. et al. // Carbon. 1997. Vol. 35. No 9. pp. 13391348.

7. Castillejos-Lopez E., Nevskaia D.M. et al. // Carbon. 2008. Vol. 46. pp. 870-875.

8. Villacañas F., Orfao M.F.R .et al. // J. Colloid and Interface Sci. 2006. Vol. 293. No 1. pp. 128-135/

9. Фазылова Г.Ф., Валинурова Э.Р. и др. // Сорбиионные и хроматографические проuесcbl. 2013. Т. 13. № 5. C.728-735.

10.March J. Advansed organic chemistry. Reactions, mechanisms and structure. New York, John Wiley \& Sons Inc. 1985. Vol. 1. 381 p.
11.Вартапетян Р.Ш., Волощук А.М // Усneхи химии. 1995. Т. 64. Вып. 11. С. 1055-1072.

12.Смирнов А.Д. Сорбционная очистка воды. Л.: Химия. 1982. 28 с.

13.Химия промышленных сточных вод. Под ред. Рубина А.М. Химия, 1983. С. 98.

14. Тарковская И.А. Окисленный уголь. Киев. Наукова думка. 1981. 200 с.

15.Беляева О.В., Краснова Т.А. и др. // Вода: химия и экология. 2012. № 5. С.81-84.

16. Amanollah E., Jafar S. et al. // Adsorption. 2009. Vol. 15. No 1. P. 65-73.

17.Котова Д.Л., Фам Тхи Гам и др. // Сорбиионные и хроматографические прочессы. 2014. T. 14. № 4. C. 572-577.

18. Barton S.S. // J. Colloid Interface Sci. 1993. Vol. 158. pp. 64-70.

19.Aranovich G.L. // J. Colloid Interface Sci. 1991. Vol. 141. No 1. pp. 30-43.

20.Adsorption from solution at the Solid/Liquid Interface. Edited by Parfitt G.D., Rochester C.H. London-New York. Academic Press Publ. 1983. 485 p.

21.Steed J.W., Atwood J.L. Supramolecular chemistry. P.1. New York, John Wiley \& Sons Ltd., 2000. 482 p. 


\section{References}

1. Koganovskii A.M., Klimenko N.A. et al. Adsorbtsiya organicheskikh veshchestv iz vodyi. Leningrad, Khimiya Publ., 1990, pp. 246.

2. Kotel'nikova T.A., Kuznecov B.V. et al., Sorbtsionnye i khromatograficheskie protsessy, 2012, Vol. 12, No 4, pp. 523-530.

3. Yang R.T. Adsorbents: fundamentals and applications. London-New York, Wiley Interscience Publ., 2003, 410 p.

4. Soldatov A.I., Vestn. Cheljab. un-ta. Ser. 4. Himija, 2004, No 1, pp. 76-80. (Rus)

5. Nevskaia D.M., Castillejos-Lopez E. et al, Carbon, 2004, Vol. 42, pp. 653-665.

6. Radovic L. R., Silva I.F. et al., Carbon, 1997, Vol. 35, No 9, pp. 1339-1348.

7. Castillejos-Lopez E., Nevskaia D.M. et al., Carbon, 2008. Vol. 46, pp. 870-875.

8. Villacañas F., Orfao M.F.R .et al., J. Colloid and Interface Sci., 2006, Vol. 293, No 1, pp. 128-135.

9. Fazylova G.F., Valinurova Je.R. et al, Sorbtsionnye i khromatograficheskie protsessy, 2013, Vol. 13, No 5, pp. 728-735.

10. March J. Advansed organic chemistry. Reactions, mechanisms and structure. New York, John Wiley \& Sons Inc., 1985, Vol. 1, 1985, $381 \mathrm{p}$.

Беляева Оксана Владимировна - к.Х.н., доцент кафедры аналитической химии и экологии Кемеровского технологического института пищевой промышленности (университета), Кемерово

Краснова Тамара Андреевна - д.т.н., професcop, зав. кафедрой аналитической химии и экологии Кемеровского технологического института пищевой промышленности (университета), Кемерово

Голубева Надежда Сергеевна к.т.Н., доцент кафедры аналитической химии и экологии Кемеровского технологического института пищевой промышленности (университета), Кемерово
11. Vartapetjan R.Sh., Voloshhuk A.M., Uspehi himii. 1995, Vol. 64, No 11, pp. 10551072.

12. Smirnov A.D. Sorbtsionnaya ochistka vodyi. Leningrad, Khimiya Publ., 1982, pp. 28.

13. Khimiya promyishlennyih stochnih vod. Edited by Rubin A.M., M., Khimiya Publ., 1983, pp. 98

14. Tarkovskaya I.A. Okislenniy ugol. Kiev, Naukova dumka Publ., 1981, pp. 200.

15. Belyaeva O.V., Krasnova T.A. et al., Voda: kcimiya i ecologiya, 2012, No 5. pp. 81-84.

16. Amanollah E., Jafar S. et al., Adsorption. 2009, Vol. 15, No 1, pp. 65-73.

17. Kotova D.L., Fam Thi Gam . et al, Sorbtsionnye i khromatograficheskie protsessy,. 2014, Vol. 14, No 45, pp. 572-577.

18. Barton S.S., J. Colloid Interface Sci., 1993, Vol. 158, pp. 64-70.

19. Aranovich G.L., J. Colloid Interface Sci., 1991, Vol. 141, No 1, pp. 30-43.

20. Adsorption from solution at the Solid/Liquid Interface. Edited by Parfitt G.D., Rochester C.H. London-New York, Academic Press Publ., 1983, 485 p.

21. Steed J.W., Atwood J.L. Supramolecular chemistry. P.1. New York, John Wiley \& Sons Ltd., 2000. 482 p.

Belyaeva Oxana V. - Ph.D. (chemistry), associate prof., department of analytical chemistry and ecology, Kemerovo Institute of Foot Science and Technology, Kemerovo, e-mail: ecolog1528@yandex.ru

Krasnova Tamara A. - grant Ph.D. (engineering sci.), prof., department of analytical chemistry and ecology, Kemerovo Institute of Foot Science and Technology, Kemerovo

Golubeva Nadezhda S. - Ph.D. (engineering sci.), associate prof., department of analytical chemistry and ecology, Kemerovo Institute of Foot Science and Technology, Kemerovo 